\title{
Polymorphism of the 5-HT transporter and response to antidepressants: randomised controlled trial ${ }^{\dagger}$
}

Glyn Lewis, Jean Mulligan, Nicola Wiles, Philip Cowen, Nick Craddock, Masashi Ikeda, Detelina Grozeva, Victoria Mason, David Nutt, Deborah Sharp, Debbie Tallon, Laura Thomas, Michael C. O'Donovan and Tim J. Peters

\section{Background}

Antidepressants exhibit a variety of pharmacological actions including inhibition of the serotonin and noradrenaline transporters. We wished to investigate whether genetic variation could be used to target or personalise treatment, in a comparison of selective serotonin reuptake inhibitors (SSRIS) with noradrenaline reuptake inhibitors (NARIS).

\begin{abstract}
Aims
To test the hypothesis that patients homozygous for the long (insertion) polymorphism of the serotonin transporter (5-HTTLPR) have an increased response to SSRI antidepressants but not to NARI antidepressants.
\end{abstract}

\section{Method}

In an individually randomised, parallel-group controlled trial, people meeting criteria for a depressive episode who were referred by their general practitioner were randomised to receive either citalopram (an SSRI) or reboxetine (an NARI). Randomisation was by means of a remote automated system accessed by telephone. The main outcome was depressive symptoms, measured by Beck Depression Inventory (BDI) total score 6 weeks after randomisation. The trial was registered with the International Standard Randomised controlled Trials Number registry (ISRCTN31345163).

\section{Results}

Altogether 298 participants were randomised to receive citalopram and 303 were randomised to reboxetine. At 6 weeks follow-up, complete data were available for 258 participants taking citalopram and 262 taking reboxetine. We found no evidence to support an influence of 5-HTTLPR on outcome following antidepressant treatment. The interaction term for BDI score at 6 weeks was 0.50 (95\% $\mathrm{Cl}-2.04$ to $3.03, P=0.70$ ), which indicated that responses to the SSRI and NARI were similar irrespective of 5-HTTLPR genotype.

\section{Conclusions}

It is unlikely that the 5-HTTLPR polymorphism alone will be clinically useful in predicting response to antidepressants in people with depression.

\section{Declaration of interest}

P.C. has been a paid member of advisory boards of Eli Lilly, Servier, wyeth and Xytis, and has been a paid lecturer for Eli Lilly, Servier and GlaxoSmithKline. He has provided expert advice for solicitors representing GlaxoSmithKline. D.N. has acted as consultant and speaker for both Lundbeck and Pfizer.
The most widely used pharmacological treatments for depression are reuptake inhibitors, which inhibit the reuptake of serotonin (5-hydroxytryptamine, 5-HT) or noradrenaline from the synapse back into the presynaptic terminal. Drugs that specifically inhibit the reuptake of 5-HT (selective serotonin reuptake inhibitors, SSRIs) now predominate in the pharmacological management of depression. However, noradrenaline reuptake inhibitors (NARIs) have broadly similar efficacy, although a network meta-analysis has suggested that reboxetine could be less effective. ${ }^{1,2}$ Antidepressants are widely prescribed. In 2007-8 in England, 34 million prescriptions for antidepressants were written, ${ }^{3}$ and in the USA the number of prescriptions rose from 154 million in 2002 to 170 million in $2005 .{ }^{4}$ The pattern of response to SSRIs is variable and so, as in other areas of medicine, it would be advantageous if one could predict response and individually tailor treatments. From the viewpoint of SSRI treatment, there has been much interest in the gene for the serotonin transporter (SLC6A4), and in particular in a 44 base pair insertion/deletion polymorphism within a repetitive unit in the promoter region (5-HTTLPR). In vitro evidence suggests the long (insertion) form of 5-HTTLPR is functionally more active than the short (deletion) form. ${ }^{5,6}$ Studies in humans are less consistent, with some evidence of enhanced serotonin transmission in those homozygous for the insertion allele, ${ }^{7}$ but no consistent support for an increase in transporter binding sites. ${ }^{8}$ There is also inconsistent evidence for the proposal

†See editorial, pp. 424-427, this issue. that SSRIs are more effective in individuals with the long/long ( $1 / 1)$ genotype. A meta-analysis has provided support (odds ratio 2.0, 95\% CI 1.4-2.9), ${ }^{9}$ but the large Sequenced Treatment Alternatives to Relieve Depression $\left(\mathrm{STAR}^{\star} \mathrm{D}\right)$ study $(n=1272)$ provided first a 'negative' finding, ${ }^{10}$ and then a 'positive' finding in a smaller subsample restricted to non-Hispanic White participants. ${ }^{11} \mathrm{~A}$ more recent meta-analysis suggested no association but used the larger STAR ${ }^{\star} \mathrm{D}$ sample in their calculations. ${ }^{12}$ Of more importance for attempts to target treatments on individuals is whether variation at 5-HTTLPR has some specific benefit for treatment with SSRIs rather than a more general influence on outcome irrespective of whether the patient is treated with an SSRI or an NARI.

Studies that have compared SSRIs with NARIs have not provided consistent findings. The Genome Based Therapeutic Drugs for Depression (GENDEP) study reported that only men with the $1 / 1$ genotype had a better response to escitalopram than to nortriptyline. ${ }^{13}$ Neither Joyce in a smaller study $(n=169)$ nor Kim et al reported a differential effect, ${ }^{14,15}$ and those in Kim's South Korean cohort with $1 / 1$ had a worse outcome for both SSRI and NARI (nortriptyline) treatment.

When comparing the effects of interventions in randomised controlled trials, CONSORT guidelines are clear that the primary outcome, the principal comparison and method of analysis should be specified in advance. ${ }^{16}$ For hypotheses such as that posed here, where the primary analyses are subgroup analyses, the need for advance specification and adequate sample size planning is 
especially important. ${ }^{17}$ We therefore conducted a randomised controlled trial, Genetic Predictors of Outcome in Depression (GENPOD), comparing an SSRI and an NARI, in which we specified the hypothesis that those with depression and the $1 / 1$ genotype of 5-HTTLPR would show a better response to the SSRI citalopram than to the NARI reboxetine.

\section{Method}

The trial methods have been reported in detail elsewhere, ${ }^{18}$ and are summarised in brief below. The study was a multicentre randomised controlled trial in which patients with depression, recruited in primary care, were randomly allocated to receive either an NARI (reboxetine $4 \mathrm{mg}$ twice daily) or an SSRI (citalopram $20 \mathrm{mg}$ daily). The study included those aged 18-74 years who had already agreed with their general practitioner (GP) that antidepressants should be prescribed. The study was conducted in three centres in the UK: Bristol, Birmingham and Newcastle. Ethical approval was obtained from the South West Ethics Committee (MREC 02/6/076) as well as research governance approval from Bristol, Birmingham and Newcastle primary care National Health Service (NHS) trusts. The trial was registered with the International Standard Randomised Controlled Trials Number registry (ISRCTN31345163) and the European Union Drug Regulating Authorities Clinical Trials (EudraCT) number is 2004-001434-16.

Patients who had taken antidepressant medication within the 2 weeks prior to the baseline assessment and those who could not complete self-administered scales were excluded. General practitioners also excluded those with medical contraindications, psychosis, bipolar affective disorder, major substance or alcohol misuse, and others whose participation was deemed inappropriate. However, we do not know how many were excluded or refused further information at this stage, before the GP referred the potential participant to the trial team. At the baseline assessment only patients with a current diagnosis of ICD-10 depressive episode F32 from the computerised Clinical Interview Schedule - Revised (CIS-R), ${ }^{19-21}$ and a Beck Depression Inventory (BDI) score above $14,{ }^{22}$ were eligible to continue in the study.

\section{Randomisation procedure}

Following the baseline assessment the participant, if eligible, was asked to consent to randomisation. Randomisation was conducted using a computer-generated code, administered centrally and communicated by telephone and thereby concealed in advance from the researcher. Allocation was stratified by severity of symptoms (CIS-R total score $\geqslant 28$ or $<28$ ) and by centre, using variable block sizes to maximise concealment. The researcher gave the randomised medication to the participant. Those randomly allocated to reboxetine were advised to begin with a dose of $2 \mathrm{mg}$ twice daily and increase it to $4 \mathrm{mg}$ twice daily after about 4 days. The patients were advised that they could approach their GP if they wished to increase the dose of antidepressant, whether citalopram or reboxetine.

\section{Sampling of DNA and genotyping}

Blood samples were taken from eligible patients in order to investigate the potential links with the 5-HT transporter (SLC6A4) gene. Their DNA was extracted using routine methods and banked at the Cardiff Medical Research Council (MRC) Centre for Neuropsychiatric Genetics and Genomics, a group with extensive experience of banking DNA under MRC guidelines. Stock DNA was stored at $-20^{\circ} \mathrm{C}$ in a linked anonymised format. All molecular genetic personnel were masked to all clinical data, including drug response.

Polymerase chain reaction (PCR) amplification was carried out with the primers $5^{\prime}$-CGCTCTGAATGCCAGCACCTAACC-3' and $5^{\prime}$-GGGATTCTGGTGCCACCTAGACGC-3', in a total volume of 121 solution containing $20 \mathrm{ng}$ genomic DNA, $0.2 \mathrm{~mol} / \mathrm{l}$ of each primer, $400 \mathrm{~mol} / \mathrm{l}$ each of deoxynucleotide triphosphate (dNTP), $4 \%$ dimethyl sulfoxide, $1.5 \mathrm{mmol} / 1 \mathrm{MgCl}_{2}, 10 \times \mathrm{PCR}$ buffer (Qiagen; www.qiagen.com) and $0.3 \mathrm{U}$ HotStarTaq (Qiagen). Initial denaturation at $95^{\circ} \mathrm{C}$ for $15 \mathrm{~min}$ was followed by 45 cycles of denaturation at $95^{\circ} \mathrm{C}$ for $20 \mathrm{~s}$, primer annealing at $60^{\circ} \mathrm{C}$ for $30 \mathrm{~s}$ and primer extension at $72^{\circ} \mathrm{C}$ for $60 \mathrm{~s}$, and a final extension reaction was performed at $72^{\circ} \mathrm{C}$ for $3 \mathrm{~min}$. The DNA fragments were resolved by electrophoresis in a 3\% agarose gel (2.5\% Metaphor Agarose, Lonza, www.lonza.com, and 0.5\% Hi-Standard Agarose, AGTC Bioproducts Ltd, www. agtcbioproducts.com) stained with ethidium bromide.

Genotypes were called by two experienced researchers working independently and masked to each other's results. For additional quality control, 166 samples were assayed again masked to the prior assigned genotypes. Concordance rates were 100\%. The overall call rate was $99 \%$. The di-allelic system was in HardyWeinberg equilibrium $(P=0.74)$.

\section{Outcome measures}

Clinical outcome data were recorded 6 weeks and 12 weeks after randomisation. The primary outcome was the total BDI score at 6 weeks. There were a number of secondary outcomes, ${ }^{18}$ and here we also report the proportion 'in remission' (defined as a total BDI score <10) at 6 weeks, Short Form Health Survey (SF-12) mental and physical subscale scores and Hospital Anxiety and Depression Scale (HADS) total scores. $^{23,24}$ Adherence to pharmacotherapy was assessed at 6 weeks by asking the patient and counting returned tablets. The participants and research assistants were aware of the randomised allocation and all outcomes were self-administered. We considered using clinicianadministered measures such as the Hamilton Rating Scale for Depression, but decided that these would be susceptible to bias in a non-masked trial. The BDI score has been widely used in depression trials.

\section{Other measures}

Life events in the previous 6 months were assessed with the following questions: 'Has someone close to you died?' 'Have you separated/divorced from your spouse/partner?' 'Has a serious illness or injury occurred to yourself or someone close to you?' 'Has a mugging, burglary or other serious assault happened to you or to someone close to you?' 'Have you or someone close to you had problems with the police involving a court appearance?' 'Have you had a serious dispute with a close friend/relative or neighbour?' 'Have you been made redundant or sacked from your job?' Responses were scored 1 for 'yes' and 0 for 'no'. Total scores could range from 0 to 7 .

\section{Statistical analysis}

An analysis plan was agreed with the trial steering committee before the results were analysed. The study was designed to test two hypotheses. As well as that stated we wished to investigate whether those with more severe depression would respond better to the NARI than to the SSRI, but the results of that analysis are not presented here because this is a distinct hypothesis with a separate literature that requires a different and extensive discussion. The primary analyses for this trial were therefore 
two pre-specified subgroup analyses for the primary outcome of BDI score at 6 weeks, with analysis performed on an intention-to-treat basis. Both of these included an interaction term between treatment and the relevant predictor variable (genotype or severity) in a multiple regression model for the primary outcome, adjusting for baseline BDI score, centre and the stratification variable of CIS-R total score $(<28$ or $\geqslant 28)$. The genotype variable was a linear term for the three-level variable: long/long (1/l), long/short (1/s) and short/short (s/s). For the power calculation the genetic hypothesis was formulated in terms of a binary variable comparing those with the $1 / 1$ genotype $v$. the remainder, so we also performed analyses to illustrate the findings using this categorisation. A further secondary analysis was performed including only participants who reported taking their allocated medication for at least 4 weeks. All differences were calculated by subtracting BDI scores for the citalopram group from those in the reboxetine group (so a positive value indicates a worse outcome for reboxetine). The reported odds ratios are the ratio of the odds of recovery for those on reboxetine to citalopram, so an odds ratio of more than 1 indicates a better response with reboxetine. We used a repeatedmeasures linear regression analysis in order to incorporate data from both the 6-week and 12-week assessments, including time in weeks as a variable in the model along with the other adjustments mentioned in the primary analysis. The main effect of genotype was studied in models without an interaction term, but retaining the other variables. We also adjusted for the time between randomisation and follow-up by incorporating it as a continuous variable in the model.

We investigated the association of baseline characteristics with missing outcome data at 6 weeks by comparing percentages of participants with missing data. The impact of missing values on our results was investigated by adjusting for factors in the regression model that were associated with missing outcome data at 6 weeks (www.missingdata.lshtm.ac.uk). This method should address any bias resulting from attrition, assuming the missing at random assumption is correct. All analyses used Stata version 10 for Windows.

\section{Justification of the sample size}

The protocol paper gives further detail on the sample size calculations and the impact that our final recruitment had on the trial. The least statistically powerful analysis was for the genotype analysis so we will summarise the power calculation for this analysis. We used the binary outcome for the BDI, remission, for the sample size calculation as this made it easier to formulate. The transporter allele was also represented as a binary variable. Both these decisions would be expected to lead to an underestimate of statistical power. Studies in the UK have observed $25 \%$ of those studied to be homozygous for the insertion allele and 50\% heterozygous. ${ }^{25,26}$ The original power calculation, based on the methods of Lubin et al,,$^{27,28}$ assumed that the proportions in remission at 6 weeks were as follows: for those in the SSRI group $80 \%$ of those homozygous for the insertion allele $(1 / 1)$ would be in remission compared with $60 \%$ for the other genotypes $(1 / \mathrm{s}$ and $\mathrm{s} / \mathrm{s})$. For those in the NARI group we assumed $65 \%$ in remission irrespective of genotype. For $90 \%$ power it was calculated this would require 754 participants in total, increased to 887 to allow for $15 \%$ attrition at 6 weeks. This corresponds to an interaction odds ratio $(\theta)$ of 0.375 (with reboxetine coded as 1 and citalopram $0 ; 1 / 1$ coded as 1 and $1 / \mathrm{s}$ plus s/s coded as 0 ).

Recruitment into the trial was less than planned and the final number randomised was 601, with a target of 570 for (primary) analysis. This target was specified in our published protocol paper. ${ }^{18}$ The actual remission rates in the trial were about $25 \%$, substantially less than the $65 \%$ expected, although similar to the results of the $\operatorname{STAR}^{\star} \mathrm{D}$ trial, which also attempted to recruit a broadly representative sample of people with depression in the USA. ${ }^{29}$ We estimated that an interaction odds ratio of 0.33 could be detected with $80 \%$ power at the $5 \%$ level, based on similar assumptions to those described earlier. This is equivalent to remission rates of $25 \%$ for the NARI group, and $36.8 \%$ and $19.1 \%$ respectively for the homozygous and remainder subgroups in the SSRI group.

\section{Results}

General practitioners from 72 practices referred 842 patients to the GENPOD study. Of these, 90 (11\%) declined to participate and 23 (3\%) were excluded prior to baseline assessment (Fig. 1). There were 126 participants ineligible at baseline and 110 did not receive a diagnosis of ICD-10 depression. Of the 729 who completed a baseline assessment, 601 were randomised between October 2005 and February 2008 to receive either citalopram $(n=298)$ or reboxetine $(n=303)$. The baseline characteristics of these groups were similar (Table 1, details shown in online Table DS1). Most of those randomised were from Bristol $(n=521)$, with the remainder from Birmingham $(n=72)$ and Newcastle $(n=8)$.

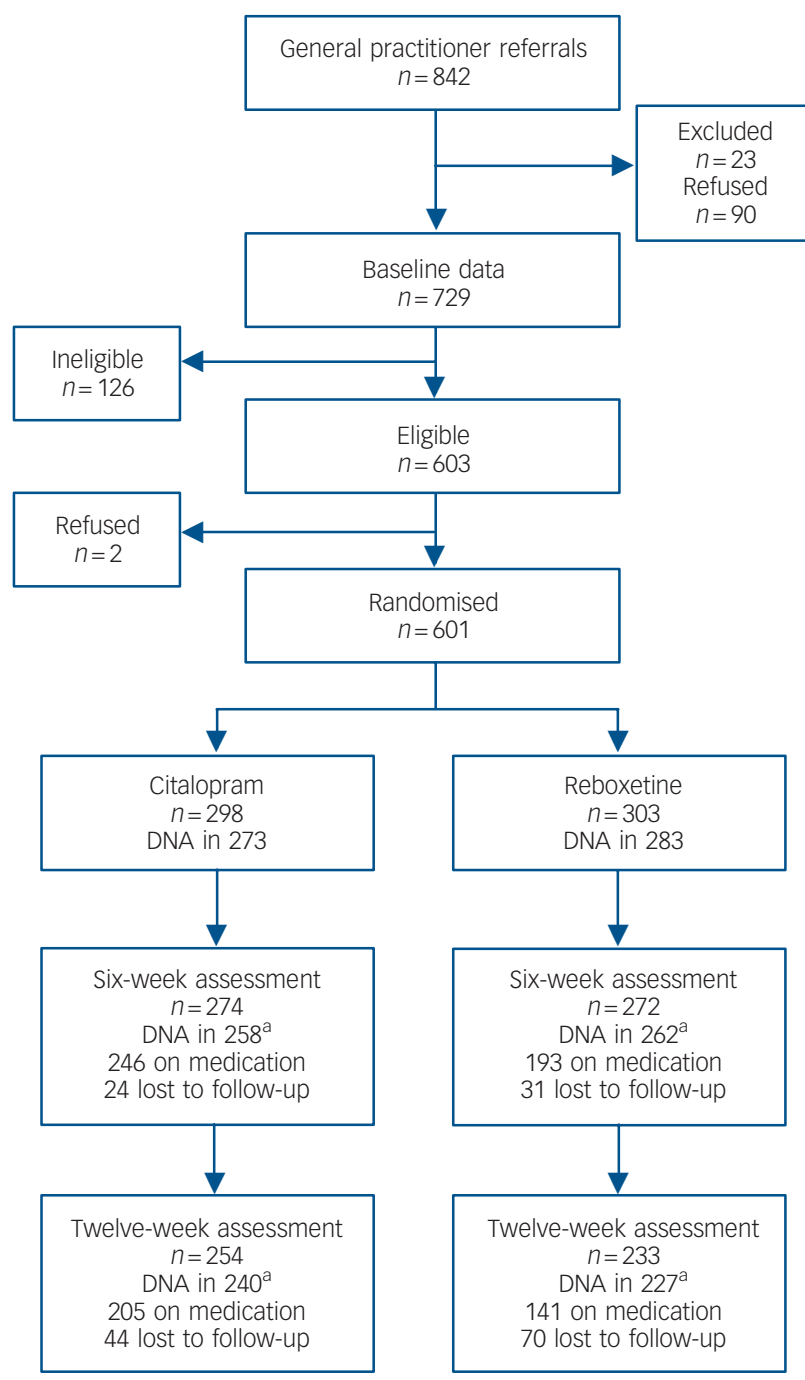

Fig. 1 Participant flow through the trial.

a. Available for analysis. 
Table 1 Baseline characteristics of randomised participants Citalopram Reboxetine group group

$(n=298)$ $(n=303)$

\begin{tabular}{|c|c|c|}
\hline \multicolumn{3}{|l|}{ Gender, $n$ (\%) } \\
\hline Male & $98(33)$ & $95(31)$ \\
\hline Female & $200(67)$ & $208(69)$ \\
\hline Age, years: mean (s.d.) & $38.6(12.1)$ & $39.1(12.6)$ \\
\hline \multicolumn{3}{|l|}{ Age group, $n(\%)$} \\
\hline 18-34 years & $122(41)$ & $124(41)$ \\
\hline $35-54$ years & $146(49)$ & $136(45)$ \\
\hline $55-74$ years & $30(10)$ & $43(14)$ \\
\hline Previous treatment, $n$ (\%) & $165(56)$ & $160(53)$ \\
\hline CIS-R score, mean (s.d.) & $31.0(7.5)$ & $30.7(8.5)$ \\
\hline \multicolumn{3}{|l|}{ Depression category, $n$ (\%) } \\
\hline Moderate $(\mathrm{CIS}-\mathrm{R}<28)$ & $102(34)$ & $105(35)$ \\
\hline Severe $(C I S-R \geqslant 28)$ & $196(66)$ & $198(65)$ \\
\hline BDI score, mean (s.d.) & $33.9(9.3)$ & $33.4(10.0)$ \\
\hline Suicidal thoughts, ${ }^{a} n(\%)$ & $38(13)$ & $43(14)$ \\
\hline Life events, mean (s.d.) & $1.7(1.3)$ & $1.6(1.4)$ \\
\hline Social support, mean (s.d.) & $11.9(3.9)$ & $12.1(3.7)$ \\
\hline \multicolumn{3}{|l|}{ Employment status, $n$ (\%) } \\
\hline Employed full-time & $114(38)$ & $129(43)$ \\
\hline Employed part-time & $55(18)$ & 59 (19) \\
\hline Student & $12(4)$ & $11(4)$ \\
\hline Retired & $6(2)$ & $15(5)$ \\
\hline Housekeeper & $45(15)$ & $32(11)$ \\
\hline Unemployed job seeker & $22(7)$ & $19(6)$ \\
\hline Unemployed owing to ill health & $44(15)$ & $38(13)$ \\
\hline $\begin{array}{l}\text { CIS-R, Clinical Interview Schedule - Revi } \\
\text { a. Patient endorsed suicidal plans on CIS } \\
\text { the BDI. }\end{array}$ & $\begin{array}{l}\text { DI, Beck Depre } \\
\text { d/or scored } 3\end{array}$ & $\begin{array}{l}\text { ventory. } \\
\text { tion } 9 \text { of }\end{array}$ \\
\hline
\end{tabular}

\section{Baseline comparability of genotype}

A blood sample was taken from 561 participants but the genotype of 5 patients could not be determined from their sample. Genotype data were available for $556(93 \%)$ randomised patients: $189(34 \%)$ of these were categorised as 1/l, $267(48 \%)$ as 1/s and $100(18 \%)$ as s/s. Although different from our assumed distribution of genotypes in the power calculation, these frequencies are in good agreement with recent estimates in a large White non-Hispanic sample from the USA, ${ }^{11}$ and with a large multicentre study sample recruited from Europe. ${ }^{13}$ Table 2 compares the characteristics of these patients according to their 5-HTTLPR genotype. Overall, the characteristics of patients were similar regardless of genotype.

\section{Follow-up}

The number of questionnaires returned at 6 weeks and at 12 weeks were $546(91 \%)$ and $487(81 \%)$ respectively. The mean time of completion for the 6-week follow-up was $43.2($ s.d.=6.4) days in the citalopram group and 44.9 (s.d. $=10)$ days for the reboxetine group $(P=0.02)$. Nine-tenths $(91 \%)$ of the 6-week follow-up questionnaires were received between 37 and 50 days after randomisation. Of those followed up at 6 weeks, 520 also had genotype data. At 6 weeks, $24(8 \%)$ of those allocated to citalopram were lost to follow-up, compared with $31(10 \%)$ in the reboxetine group. There were 520 participants with both 6-week outcome data and genotype data ( $87 \%$ of the randomised sample).

\section{Adherence}

Reboxetine appeared to be less well tolerated than citalopram. At 6 weeks, $36 \%$ of patients randomised to reboxetine had stopped

\begin{tabular}{|c|c|c|c|c|}
\hline & \multicolumn{3}{|c|}{ Genotype } & \multirow[b]{2}{*}{$P^{a}$} \\
\hline & $\mathrm{I} / \mathrm{I}(n=189)$ & $1 / \mathrm{s}(n=267)$ & $\mathrm{s} / \mathrm{s}(n=100)$ & \\
\hline Gender, $n$ (\%) & & & & 0.13 \\
\hline Male & $71(38)$ & $77(29)$ & $35(35)$ & \\
\hline Female & $118(63)$ & $190(71)$ & $65(65)$ & \\
\hline Age, years: mean (s.d.) & $39.5(12.4)$ & $38.8(12.6)$ & $39.1(12.3)$ & 0.86 \\
\hline Ethnicity, $n$ (\%) & & & & 0.14 \\
\hline White & $179(95)$ & $257(96)$ & $97(97)$ & \\
\hline Mixed & $1(1)$ & $2(1)$ & $0(0)$ & \\
\hline Asian/British Asian & 1 (1) & $3(1)$ & $2(2)$ & \\
\hline Black/Black British & $8(4)$ & $5(2)$ & $0(0)$ & \\
\hline Other & $0(0)$ & $0(0)$ & $1(1)$ & \\
\hline History of depression, $n$ (\%) & $128(68)$ & $201(75)$ & $76(77)$ & 0.13 \\
\hline Previous antidepressant treatment, $n(\%)$ & $95(51)$ & $160(60)$ & $52(53)$ & 0.12 \\
\hline Family history of depression, $n(\%)$ & $116(62)$ & $169(63)$ & $64(65)$ & 0.85 \\
\hline BDI score, mean (s.d.) & $33.3(9.6)$ & $34.2(9.9)$ & $33.3(9.1)$ & 0.55 \\
\hline Suicidal thoughts, $n$ (\%) & $26(14)$ & $36(13)$ & $12(12)$ & 0.91 \\
\hline Life events, mean (s.d.) & $1.6(1.4)$ & $1.8(1.4)$ & $1.5(1.3)$ & 0.15 \\
\hline Social support, mean (s.d.) & $11.8(4.0)$ & $12.3(3.6)$ & $12.0(3.8)$ & 0.32 \\
\hline Employment status, $n$ (\%) & & & & 0.25 \\
\hline Employed full-time & $75(40)$ & $106(40)$ & $43(43)$ & \\
\hline Employed part-time & $40(21)$ & $46(17)$ & $22(22)$ & \\
\hline Student & $8(4)$ & 7 (3) & $5(5)$ & \\
\hline Retired & 7 (4) & $11(4)$ & 3 (3) & \\
\hline Housekeeper & $19(10)$ & $41(15)$ & $9(9)$ & \\
\hline Unemployed jobseeker & $20(11)$ & $13(5)$ & $6(6)$ & \\
\hline Unemployed owing to ill health & $20(11)$ & $43(16)$ & $12(12)$ & \\
\hline
\end{tabular}


Table 3 Beck Depression Inventory (BDI) mean scores and adjusted differences at 6 weeks according to 5-HTTLPR genotype

\begin{tabular}{|c|c|c|c|c|c|}
\hline \multirow[b]{2}{*}{ Genotype } & \multicolumn{2}{|c|}{ Citalopram group } & \multicolumn{2}{|c|}{ Reboxetine group } & \multirow{2}{*}{$\begin{array}{l}\text { Difference (reboxetine minus citalopram) } \\
\text { Adjusted difference }(95 \% \mathrm{Cl})\end{array}$} \\
\hline & $n$ & BDI score, mean (s.d.) & $n$ & BDI score, mean (s.d.) & \\
\hline $1 / 1$ & 79 & $18.1(10.1)$ & 99 & $18.5(10.8)$ & $1.03(-1.90$ to 3.96$)$ \\
\hline $1 / \mathrm{s}$ & 130 & $19.6(11.6)$ & 120 & $20.3(11.2)$ & $0.94(-1.69$ to 3.57$)$ \\
\hline $\mathrm{s} / \mathrm{s}$ & 49 & $18.0(10.9)$ & 43 & $19.7(11.8)$ & $1.90(-2.47$ to 6.27$)$ \\
\hline
\end{tabular}

taking the allocated medication compared with $17 \%$ for citalopram. For those with outcome data at 6 weeks, $91.2 \%$ (250 of 274) had taken citalopram for at least 4 weeks and $82.4 \%$ (224 of 272) had taken reboxetine for at least 4 weeks. Some of the participants also received additional quantities of their randomised medication from their GP. For those prescribed citalopram, 11 patients had their daily dosage increased to $30 \mathrm{mg}, 33$ patients had it increased to $40 \mathrm{mg}$ and 11 patients to $60 \mathrm{mg}$ ( 1 further participant had an increase in prescribed dose of an unknown amount). For reboxetine, 3 patients had an increase in daily dosage to $10 \mathrm{mg}, 9$ patients had an increase to $12 \mathrm{mg}$ and 1 patient's dosage was increased to $16 \mathrm{mg}$.

\section{Analysis for the genotype hypothesis}

Table 3 reports the mean BDI scores at 6 weeks and the differences in response between citalopram and reboxetine according to genotype. At 6 weeks the difference between citalopram and reboxetine was greater for those with the s/s genotype. The primary analysis was to test for an interaction between genotype and allocated treatment, with 6-week BDI scores as the outcome, adjusting for baseline BDI score, severity stratum and centre. This analysis provided no evidence for a differential effect (interaction term $0.50,95 \%$ CI -2.04 to $3.03, P=0.70)$. Restricting this regression to the 451 participants with 6-week follow-up data who reported taking their allocated medication for at least 4 weeks led to results well within the confidence intervals of the primary analysis (interaction term $-0.72,95 \%$ CI -3.40 to 1.95 , $P=0.60$ ). Adjusting the primary analysis for the time interval between randomisation and 6-week follow-up led to little difference (interaction term $0.49,95 \%$ CI -2.05 to 3.02 , $P=0.71$ ), nor did restricting the analysis to patients of White ethnic origin (interaction term $0.39,95 \%$ CI -0.22 to 2.99 , $P=0.77 ; n=499$ ). We also investigated a main effect of genotype on outcome, irrespective of treatment, after adjustment for the random allocation and the other adjustments listed. We found no evidence for any association between genotype and outcome at 6 weeks (mean BDI score difference $0.49,95 \%$ CI -0.78 to $1.76, P=0.58)$ in the whole sample, nor when we restricted the analysis to those receiving citalopram (mean BDI score difference $0.25,95 \%$ CI -1.64 to 2.15$)$. We studied the influence of genotype on outcome in a repeated-measures analysis in which both 6-week and 12-week data were used. The results for the interaction term were similar (mean BDI score difference 0.41, $95 \%$ CI -1.96 to $2.78, P=0.73$ ), even when the analysis was restricted to those of White ethnic origin (interaction term 0.38 , $95 \%$ CI -2.04 to 2.81 ) in order to address potential population stratification.

\section{Secondary outcomes}

We also examined our secondary outcomes, the HADS score and the SF-12 standardised mental and physical subscales, in relation to the study hypothesis (online Tables DS2-4). The interaction terms for these outcomes were as follows: HADS score -0.09 (95\% CI -2.04 to 1.85 ); SF-12 mental subscale score -0.13 ( $95 \%$ CI -3.06 to 2.79 ); SF-12 physical subscale score -0.57 (95\% CI -2.51 to 1.36 ). Again, there was no evidence to support an interaction between genotype and treatment allocation. We also carried out repeated-measures analyses on these secondary outcomes, using the same approach as for the primary outcome. The interaction terms were as follows: HADS score $0.20(95 \%$ CI -1.63 to 2.03 ), SF-12 mental subscale score -0.80 (95\% CI -3.38 to 1.78 ), and SF-12 physical subscale score 0.17 (95\% CI -1.58 to 1.91$)$.

\section{Size of possible interaction effects}

To further illustrate the results in relation to the power calculation, we carried out an analysis in which both the genotype and outcome were dichotomous, the interaction odds ratio was 1.07 (95\% CI 0.58 to 2.12 ) compared with the target interaction odds ratio in the sample size calculation of 0.33 . In addition, Table 4 shows the percentages in remission at 6 weeks according to the dichotomous genotype exposures. The original hypothesis argued for a larger difference between the genotypes in the citalopram group, and no difference in the reboxetine group. The results clearly do not support this hypothesis.

\section{Missing data}

Although overall levels of attrition were low at 6 weeks (Fig. 1), an exploratory analysis found that participants who were younger, and with more life events and less social support were more likely to have missing data at 6 weeks (online Table DS5). Adjustment for these variables had no effect on the main interaction for genotype, if anything reducing it towards the null (interaction term BDI score $0.25,95 \% \mathrm{CI}-2.27$ to $2.76, P=0.85$ ).

\section{Discussion}

This study was designed to test the hypothesis that 5-HTTLPR leads to a differential response to SSRIs and NARIs in depression. We did not find any evidence to support this suggestion. The main strength of our study was our efforts to reduce the possibility of a chance finding. This was accomplished by prior publication of our protocol and hypotheses, and by preparation of a detailed analysis

Table 4 Percentage of patients in remission at 6 weeks according to medication and 5-HTTLPR genotype

\begin{tabular}{|lcc|}
\hline Genotype & $\begin{array}{c}\text { Citalopram group } \\
\%(95 \% \mathrm{Cl})\end{array}$ & $\begin{array}{c}\text { Reboxetine group } \\
\%(95 \% \mathrm{Cl})\end{array}$ \\
\hline $\mathrm{I} / \mathrm{I}$ & $24.1(15.1-34.0)$ & $25.3(17.1-35.0)$ \\
\hline I/S, S/S & $22.4(16.5-29.2)$ & $20.9(14.9-27.9)$ \\
\hline I, long; s, short. & & \\
\hline
\end{tabular}


plan that restricted opportunities for multiple analytical approaches and selective reporting. The main limitation in drawing definitive conclusions concerns the statistical power of the study. Can we conclude that there is no influence of 5-HTTLPR on response to SSRIs? If not, have we at least obtained a result that makes it unlikely that a clinically important interaction is present? Our results exclude the possibility, at least in statistical terms, of an interaction of the size used in our power calculation based on a difference we considered to be clinically important. We have also excluded an interaction of more than 3 points on the BDI (about 0.3 standard deviation). There is no generally accepted definition of a clinically important difference in research on depression but we think that our study was sufficiently large to exclude the possibility of a clinically important interaction between 5-HTTLPR and response to SSRI antidepressants. We have concluded that, given the uncertainties about the assumptions underpinning the power calculations, the shortfall in recruitment had a relatively modest impact on the ability of the trial to answer the primary research questions posed.

For a number of reasons we may have underestimated the influence of 5-HTTLPR on outcome. There was only partial adherence to the medication regimen and this would have made it more difficult to detect any difference. However, restricting the analysis to those who took medication for at least 4 weeks did not alter our findings. Attrition is often a problem in clinical trials, but there was good follow-up response at 6 weeks of $87 \%$ once the genotype data had been taken into account. Moreover, adjustment for factors associated with missing data did not influence our conclusions. Finally, depression treated in primary care is often considered to be of mild to moderate severity. In the GENPOD study the mean score on the BDI was about 33 at baseline, indicating that the population included was experiencing depressive illness of at least moderate severity and at a level that one would expect a response to medication. We had a similar response rate to that observed in the STAR ${ }^{\star} \mathrm{D}$ study. ${ }^{29}$

When considering genetic predictors of antidepressant outcome there is a real danger of reporting type 1 (false positive) errors. Even when analysis is restricted to functional candidate genes, whose function is plausibly related to a target phenotype, there are a large number of polymorphisms which can be analysed using a variety of genetic models. The outcome of depression is usually rated as a continuous score and so the analysis can either use a continuous score or define categories such as response (usually a $50 \%$ reduction in score) or remission (below a threshold score). Finally, it is never entirely clear whether genetic hypotheses have been stated beforehand, or whether the statistically significant results have been selected post hoc (especially when two-way interactions are then reported in subgroups such as within-gender). The analysis of subgroups within clinical trials has also received much criticism because of the loss of statistical power and that the many possible effectmodifiers might increase the risk of type 1 errors. ${ }^{30}$ The impact of such publication and reporting biases are amplified in systematic reviews of the area. ${ }^{31}$

Within SLC6A4 there are many variants in and around 5-HTTLPR that could be tested, several of which have been reported to be functional or associated with a range of psychiatric phenotypes, including antidepressant response. ${ }^{10,13,32}$ In particular, a report that haplotypes constructed from polymorphism rs25531 and 5-HTTLPR are functional and associated with obsessivecompulsive disorder has attracted some interest; ${ }^{33}$ however, the association between the rs25531/5-HTTLPR haplotypes and the disorder has not been confirmed, ${ }^{34}$ and the functionality of this variant is still controversial. ${ }^{35,36}$ Moreover, there is no previous evidence that the haplotype is associated with antidepressant response, ${ }^{10,13,37}$ except for one report of borderline statistical significance, uncorrected for multiple testing, coming from a small study of 96 participants in which one of the groups (non-responders) contained only 17 individuals. $^{32}$ Given the above, we decided that there were insufficient grounds for modifying the predefined design of this study by incorporating this marker at SLC6A4.

Our results appear to contradict earlier study findings, including the meta-analysis of Serretti et al, ${ }^{9}$ but the latter authors did not investigate or discuss the possibility of a publication bias accounting for their findings. Furthermore, our results are supported by the large STAR ${ }^{\star} \mathrm{D}$ sample that - at least in the first published analysis - found no association between 5-HTTLPR and outcome. ${ }^{10}$ The subsequent $\mathrm{STAR}^{*} \mathrm{D}$ analysis on the more ethnically homogeneous subsample was only of borderline significance, ${ }^{11}$ and used a different definition of remission which was not fully justified in the published papers. In the future it would be useful to combine samples and use similar analytical approaches in order to arrive at some consensus about these findings. The generalisability of these results also needs discussion. The presentation and treatment of depression varies between different health systems. Furthermore, it is difficult to obtain a truly representative sample of people, even with treated depression, because of its presentation in primary care. However, it is reassuring that the response rates to antidepressants in our study were similar to those reported in $\operatorname{STAR}^{\star} \mathrm{D},{ }^{29}$ a study that also attempted to obtain a broadly representative sample of people with depression within the very different US healthcare system. We therefore think that our conclusion that 5-HTTLPR does not influence antidepressant response is at least generalisable to other populations of European origin.

We have considered three possible explanations for our negative result in relation to the 5-HTTLPR gene. First, that the 5-HTTLPR does not alter the availability of 5-HT transporters in the adult human brain. This hypothesis has some support from recent ligand imaging studies that have failed to find convincing differences in 5-HT transporter availability according to 5-HTTLPR. ${ }^{8}$ Second, even if 5-HT transporter availability is altered, that the influence of 5-HTTLPR on SSRI-induced changes in serotonin neurotransmission is minimal. The SSRIs block over $80 \%$ of available 5 -HT transporters at minimum therapeutic doses, ${ }^{38}$ so therapeutic response is unlikely to be affected by relatively small differences in transporter availability. Furthermore, even if this polymorphism affects the number of transporter molecules it is possible that compensatory changes in postsynaptic or presynaptic mechanisms might act to maintain steady 5-HT transmission. Neurodevelopmental processes could also have led to brain changes earlier in life in order to minimise any impact that the 5-HTTLPR polymorphism might have on brain function in adults.

The final explanation we have considered is that genetic effects on pharmacological response could be very small. It has become apparent that even if there is a substantial genetic component to a complex disorder this is likely to result from the action of a large number of alleles that individually have a small effect at population level, either because alleles with large effects in individuals are rare in the population, or because common alleles have weak effects on individual risk. ${ }^{39}$ We cannot rule out a small influence of the 5-HTTLPR variant on outcome, but we think it is unlikely that variation at this locus provides sufficient information to be clinically useful. Of course, it is possible that the predictive value could be improved by combining information from several variants within the gene, or from several genes. ${ }^{40}$ We think it may be useful to think of recovery from an illness such as depression in the same way as we think of the aetiology of complex diseases. ${ }^{41}$ 
Recovery from depression is also a multifaceted process that will be influenced by a large number of biological, psychological and social variables. In order to study genes affecting outcome, it is likely that we will need to adopt a similar approach to that used for studying the genetic aetiology of illness, always remembering the other environmental and treatment factors that might also be important.

Glyn Lewis, PhD, FRCPsych, Jean Mulligan, BSC, PhD, Nicola wiles, BSC, PhD, School of Social and Community Medicine, University of Bristol; Philip Cowen, MD, FRCPsych, Department of Psychiatry, University of Oxford; Nick Craddock, PhD, FRCPsych, Masashi Ikeda, MD, PhD, Detelina Grozeva, MSC, Medical Research Council (MRC) Centre for Neuropsychiatric Genetics and Genomics, School of Medicine, Cardiff University; Victoria Mason, BSc, MSc, PhD, CPsychol, Institute of of Health Sciences, University of Worcester, David Nutt, DM, FRCP, FRCPSych, FMedSci, Department of Neuropsychopharmacology, Imperial College London; Deborah Sharp, MA, BM, BCh, PhD, FRCGP, Debbie Tallon, BSC, MSC, Laura Thomas, BA, MPhil, School of Social and Community Medicine, University of Bristol; Michael C. O'Donovan, PhD, FRCPsych, MRC Centre for Neuropsychiatric Genetics and Genomics, School of Medicine, Cardiff University; Tim J. Peters, BSC, MSc, PhD, CStat, FFPH, School of Social and Community Medicine, University of Bristol, UK

Correspondence: Glyn Lewis, School of Social and Community Medicine, University of Bristol, Cotham House, Cotham Hill, Bristol BS6 6JL, UK. Email: Glyn.lewis@bristol.ac.uk

First received 19 May 2010, final revision 6 Aug 2010, accepted 11 Aug 2010

\section{Funding}

The study was funded by the Medical Research Council and supported by the Mental Health Research Network.

\section{Acknowledgements}

We are grateful for the support of the patients who agreed to participate and their general practitioners. We would like to thank the members of the trial steering committee: Ian practitioners. We would like to thank the members of the trial steering committee: lan
Anderson (Chair), Tony Johnson, John Geddes and Rodney Elgie, and members of the data Anderson (Chair), Tony Johnson, John Geddes and Rodney Elgie, and members of the data
monitoring committee: Linda Gask (Chair), Nick Freemantle and Irwin Nazareth. We thank the people who contributed towards the fieldwork, including the following: Helen Lester, Laura Webber, Morag Turnbull, Louise Paterson, Ben Newton, Alex Smith, Nicola Morris, Leigh Franks, Joy Farrimond, Nathan Filer, Caitlin Jarrett and Angela Hill.

\section{References}

1 Freemantle N, Anderson IM, Young P. Predictive value of pharmacological activity for the relative efficacy of antidepressant drugs. Meta-regression analysis. Br J Psychiatry 2000; 177: 292-302.

2 Cipriani A, Furukawa TA, Salanti G, Geddes JR, Higgins JP, Churchill R, et al. Comparative efficacy and acceptability of 12 new-generation antidepressants: a multiple-treatments meta-analysis. Lancet 2009; 373: 746-58.

3 Prescribing Support Unit. Prescribing Monitoring Report April 2007 - March 2008. Leeds Information Centre for Health and Social Care, 2008.

4 Medical Expenditure Panel Survey. Antidepressants Prescribed by Medical Doctors in Office Based and Outpatient Settings by Specialty for the US Civilian Noninstitutionalized Population, 2002 and 2005. US Agency for Healthcare Research and Quality, 2008.

5 Lesch KP, Bengel D, Heils A, Sabol SZ, Greenberg BD, Petri S, et al. Association of anxiety-related traits with a polymorphism in the serotonin transporter gene regulatory region. Science 1996; 274: 1527-30.

6 Laux G, Konig W, Lesch KP, Stein A. Intravenous versus oral treatment of endogenously depressed patients with doxepin - a double-blind study with plasma level determination. Wien Med Wochenschr 1989; 139: 525-9.

7 Whale R, Quested DJ, Laver D, Harrison PJ, Cowen PJ. Serotonin transporter (5-HTT) promoter genotype may influence the prolactin response to clomipramine. Psychopharmacology 2000; 150: 120-2.

8 Murthy NV, Selvaraj S, Cowen P, Bhagwagar Z, Riedel WJ, Peers P, et al. Serotonin transporter polymorphisms (SLC6A4 insertion/deletion and rs25531) do not affect availability of 5-HTT to [11C] DASB binding in the living human brain. Neuroimage 2010; 52: 50-4.

9 Serretti A, Kato M, De RD, Kinoshita T. Meta-analysis of serotonin transporter gene promoter polymorphism (5-HTTLPR) association with selective serotoni reuptake inhibitor efficacy in depressed patients. Mol Psychiatry 2007; 12: 247-57
$10 \mathrm{Hu}$ XZ, Rush AJ, Charney D, Wilson AF, Sorant AJ, Papanicolaou GJ, et al. Association between a functional serotonin transporter promoter polymorphism and citalopram treatment in adult outpatients with major depression. Arch Gen Psychiatry 2007; 64: 783-92.

11 Mrazek DA, Rush AJ, Biernacka JM, O'Kane DJ, Cunningham JM, Wieben ED, et al. SLC6A4 variation and citalopram response. Am J Med Genet $B$ Neuropsychiatr Genet 2009; 150B: 341-51.

12 Taylor MJ, Sen S, Bhagwagar Z. Antidepressant response and the serotonin transporter gene-linked polymorphic region. Biol Psychiatry 2010; 68 $536-43$

13 Huezo-Diaz P, Uher R, Smith R, Rietschel M, Henigsberg N, Marusic A, et al. Moderation of antidepressant response by the serotonin transporter gene. Br J Psychiatry 2009; 195: 30-8.

14 Joyce PR, Mulder RT, Luty SE, McKenzie JM, Miller AC, Rogers GR, et al. Age-dependent antidepressant pharmacogenomics: polymorphisms of the serotonin transporter and $\mathrm{G}$ protein beta3 subunit as predictors of response to fluoxetine and nortriptyline. Int J Neuropsychopharmacol 2003; 6: 339-46.

15 Kim H, Lim SW, Kim S, Kim JW, Chang YH, Carroll BJ, et al. Monoamine transporter gene polymorphisms and antidepressant response in koreans with late-life depression. JAMA 2006; 296: 1609-18.

16 Moher D, Schulz KF, Altman DG. The CONSORT statement: revised recommendations for improving the quality of reports of parallel-group randomized trial. Lancet 2001; 357: 1191-4.

17 Patsopoulos NA, Tatsioni A, Ioannidis JP. Claims of sex differences: an empirical assessment in genetic associations. JAMA 2007; 298: 880-93.

18 Thomas L, Mulligan J, Mason V, Tallon D, Wiles N, Cowen P, et al. Genetic and clinical predictors of treatment response in depression: the GenPod randomised trial protocol. Trials 2008; 9: 29.

19 World Health Organization. The ICD-10 Classification of Mental and Behavioural Disorders. WHO, 1992.

20 Lewis G, Pelosi AJ, Araya R, Dunn G. Measuring psychiatric disorder in the community: a standardised assessment for use by lay interviewers. Psychol Med 1992; 22: 465-86.

21 Lewis G. Assessing psychiatric disorder with a human interviewer or a computer. J Epidemiol Commun Health 1994; 48: 207-10.

22 Beck AT, Ward $\mathrm{CH}$, Mendelsohn M, Mock J, Erbaugh J. An inventory for measuring depression. Arch Gen Psychiatry 1961; 4: 561-71.

23 Jenkinson C, Layte R. Development and testing of the UK SF-12 (short form health survey). J Health Serv Res Policy 1997; 2: 14-8.

24 Zigmond A, Snaith R. The hospital anxiety and depression scale. Acta Psychiatr Scand 1983; 67: 361-70.

25 Kirov G, Rees M, Jones I, MacCandless F, Owen MJ, Craddock N. Bipola disorder and the serotonin transporter gene: a family-based association study. Psychol Med 1999; 29: 1249-54.

26 Ogilvie AD, Battersby S, Bubb VJ, Fink G, Harmar AJ, Goodwim GM, et al. Polymorphism in the serotonin transporter gene associated with susceptibility to major depression. Lancet 1996; 347: 731-3.

27 Lubin $\mathrm{JH}$, Gail $\mathrm{MH}$. On power and sample size for studying features of the relative odds of disease. Am J Epidemiol 1990; 131: 552-66.

28 Garcia-Closas M, Lubin JH. Power and sample size calculations in casecontrol studies of gene-environmental interactions: comments on different approaches. Am J Epidemiol 1999; 149: 689-93.

29 Trivedi MH, Rush AJ, Wisniewski SR, Nierenberg AA, Warden D, Ritz L, et al. Evaluation of outcomes with citalopram for depression using measurementbased care in STAR*D: implications for clinical practice. Am J Psychiatry 2006: 163: $28-40$

30 Brookes ST, Whitley E, Egger M, Davey Smith G, Mulheran P, Peters TJ. Subgroup analyses in randomised controlled trials: risks of sub-group specific analyses; power and sample size for the interaction test. $J$ Clin Epidemiol 2004; 57: 229-36.

31 Ioannidis JP, Trikalinos TA. An exploratory test for an excess of significant findings. Clin Trials 2007; 4: 245-53.

32 Kraft JB, Slager SL, McGrath PJ, Hamilton SP. Sequence analysis of the serotonin transporter and associations with antidepressant response. Biol Psychiatry 2005; 58: 374-81.

33 Hu XZ, Lipsky RH, Zhu G, Akhtar LA, Taubman J, Greenberg BD, et al. Serotonin transporter promoter gain-of-function genotypes are linked to obsessive-compulsive disorder. Am J Hum Genet 2006; 78: 815-26.

34 Wendland JR, Kruse MR, Cromer KR, Murphy DL. A large case-control study of common functional SLC6A4 and BDNF variants in obsessive-compulsive disorder. Neuropsychopharmacology 2007; 32: 2543-51.

35 Parsey RV, Hastings RS, Oquendo MA, Hu X, Goldman D, Huang YY, et al. Effect of a triallelic functional polymorphism of the serotonin-transporterlinked promoter region on expression of serotonin transporter in the human brain. Am J Psychiatry 2006; 163: 48-51. 
36 Martin J, Cleak J, Willis-Owen SA, Flint J, Shifman S. Mapping regulatory variants for the serotonin transporter gene based on allelic expression imbalance. Mol Psychiatry 2007: 12: 421-2.

37 Kraft JB, Peters EJ, Slager SL, Jenkins GD, Reinalda MS, McGrath PJ, et al. Analysis of association between the serotonin transporter and antidepressant response in a large clinical sample. Biol Psychiatry 2007; 61: 734-42.

38 Meyer JH, Wilson AA, Ginovart N, Goulding V, Hussey D, Hood K, et al. Occupancy of serotonin transporters by paroxetine and citalopram during treatment of depression: a [(11)C]DASB PET imaging study. Am J Psychiatry 2001; 158: 1843-9.

39 Risch NJ. Searching for genetic determinants in the new millennium. Nature 2000; 405: 847-56.

40 Evans DM, Visscher PM, Wray NR. Harnessing the information contained within genome-wide association studies to improve individual prediction of complex disease risk. Hum Mol Genet 2009; 18: 3525-31.

41 Rothman KJ, Greenland S. Causation and causal inference in epidemiology. Am J Public Health 2005; 95 (suppl 1): S144-50.

\section{Insights into humanity}

\section{Suhanthini Farrell}

As a core trainee in old age psychiatry, I always look forward to the part of the Mini-Mental State Examination (MMSE) when I turn over the piece of paper, hand over my pen, and invite the patient to 'write a sentence - anything you like, whatever comes into your mind'. Most are initially flummoxed by this - it is not often, after all, that we are asked to put the everyday thoughts floating around in our heads into words - but then produce something that gives me a startling insight into their personal world. It provides a valuable reminder that no matter how cognitively impaired the person in front of me may be, they have the same feelings, anxieties and thoughts as anyone else. From all the MMSEs I have done, I have compiled a list of my personal favourites.

From the mundane:

'We are having fish and chips for tea.'

'My cat's full name is Mr Boo Stinkweed Tinkerbell.'

'I have put a blue sock in the white wash oh no oh no.'

to the poignant:

'I loved my husband very much.'

'I miss my daughter Janie every day.'

'Please don't take me away.'

From the sublime:

'Rough winds do shake the darling buds of May

And summer's lease hath all too short a date.'

to the less so:

'I need a poo.

From the complimentary:

'You have beautiful hair doctor'

'You smell very nice.'

to my all-time favourite, from the sweetest-looking 92-year-old lady:

'What the $f^{\star * * i n g ~ h e l l ~ a r e ~ y o u ~ l o o k i n g ~ a t ? ' ~}$ 